\title{
RESPON SEMAI BAMBANG LANANG (Michelia champaca L.) TERHADAP PEMBERIAN ASAP CAIR
}

\author{
Deselina*, Putranto Budiono Agung Nugroho, Meika Ayu Putri Pamungkas \\ Program Studi Kehutanan, Fakultas Pertanian, Universitas Bengkulu \\ Jl. WR. Supratman, Kandang Limun Bengkulu \\ *E-mail : deselina@ymail.com
}

\begin{abstract}
ABSTRAK
Penelitian ini bertujuan untuk mengetahui respon semai bambang lanang terhadap pemberian asap cair Variabel yang diamati adalah tinggi, diameter, luas daun panjang akar, berat berangkasan basah, berat berangkasan kering dan indeks mutu semai. Data dianalisis menggunakan uji t dua variabel yaitu : perlakuan dan kontrol, konsentrasi dan kontrol dan antara konsentrasi. Hasil penelitian menunjukkan bahwa pengaruh penggunaan asap cair tidak berbeda nyata terhadap pertumbuhan bibit bambang lanang, namun memberikan ratarata yang lebih besar dari pada kontrol . Antara konsentrasi asap cair terdapat perbedaan nyata terhadap tinggi, jumlah daun, panjang akar, berat basah total dan berat kering total. Penggunaan asap cair 2\% adalah yang paling optimal untuk meningkatkan rata-rata beberapa variabel pertumbuhan bibit bambang lanang dubandingkan dengan konsentrasi $1 \%, 3 \%$ dan $4 \%$.
\end{abstract}

Kata Kunci : asap cair, semai Bambang Lanang

\section{BAB 1}

\section{PENDAHULUAN}

Tanaman Bambang Lanang (Michelia champaca L.) merupakan jenis pohon lokal yang ada di Sumatera Selatan. Saat ini Bambang lanang sudah menyebar sampai propinsi Bengkulu yang dimanfaatkan sebagai kayu pertukangan (Martin dan Premono, 2010). Pohon Bambang Lanang memiliki buah yang banyak dan memiliki bebas cabang tinggi sehingga potensial dikembangkan menjadi bibit.

Secara ekonomis saat ini Bambang Lanang memiliki harga yang cukup baik sehingga jenis ini sudah dikembangkan secara luas. Pola agroforestri dengan tanaman kayu Bambang Lanang yang dikembangkan secara turun menurun di Ulu
Musi , Lahat telah mampu mencukupi kebutuhan masyarakat dan bahkan memperbaiki masa depan anak-anak mereka (Martin $d k k$, 2003). Hal ini menunjukkan bahwa jenis-jenis tanaman local cukup potensial untuk dikembangkan di hutan rakyat. Produktivitas Bamban g lanang yang dihasilkan dari lahan kebun masyarakat dilaporkan rata-rata sebesar $13 \mathrm{~m}^{3} / \mathrm{ha} / \mathrm{th}$ (Sofyan, $d k k$. 2010). Sementara target yang diamanatkan dalam Road Map Badan Litbang Kehutanan 2010-2025 untuk jenis alternative daur menengah ( $>10$ th) seperti jenis Bambang Lanang adalah $15 \mathrm{~m}^{3} / \mathrm{ha} / \mathrm{th}$ (Departemen Kehutanan, 2009).

Asap cair atau cuka kayu merupakan cairan warna kuning kecoklatan/coklat kehitaman yang diperoleh dari hasil samping pembuatan arang (Komarayati $d k k, 2011$ dan 
Nurhayati, 2007). Kandungan utama asap cair adalah senyawa fenol, benzopiren dan beberapa asam organic yang dapat meningkatkan pertumbuhan tanaman. Komarayati dan Wibisono (2016) melaporkan bahwa pertumbuhan anakan Shorea platyclados dan Shorea selanica meningkat karena penambahan arang dan asap cair. Gusmailina $d k k$ (2018) menyatakan bahwa penggunaan asap cair pada konsentrasi $4 \%$ paling prospektif untuk menggiatkan pertumbuhan anakan Gyrinops sp serta penelitian pengaruh asap cair lainnya mampu meningkatkan pertumbuhan pada tanaman sengon, jabon dan pohon penghasil gaharu (Komarayati $d k k, 2014$, Komarayati dan Pari, 2014). Peran asap cair dalam meningkatkan kualitas tanaman perlu diuji coba pada jenis tanaman kehutanan yang lainnya seperti Bambang Lanang.

Tujuan dari penelitian ini adalah untuk mengetahui respon bibit Bambang Lanang terhadap pemberian asap cair pada berbagai konsentrasi.

\section{BAB II METODE PENELITIAN}

\subsection{Waktu dan Tempat}

Penelitian dilaksanakan pada bulan April - Oktober 2019 di persemaian Laboratorium Kehutanan Universitas Bengkulu.

\subsection{Alat dan Bahan}

Alat yang digunakan adalah timbangan analitk, suntikan (100 ml), thermometer, oven, caliper, penggaris, lux meter, kamera. Hygrometer, dan jerigen

Bahan untuk penelitian : semai bambang lanang umur 1 bulan, asap cair/cuka kayu (tingkat crude), tanah topsoil + kompos, air, polybag berukuran $18 \mathrm{~cm} \mathrm{x}$ $20 \mathrm{~cm}$, insektisida desis $25 \mathrm{EC}$

Data didapat dari perlakuan tanaman yang disusun dengan :
Konsentrasi asap cair, yaitu : 1\%. 2\%, 3\% dan $4 \%$ dengan dosis $0,2 \mathrm{ml}-4 \mathrm{ml}$

Masing-masing konsentrasi terdiri dari 18 unit tanaman, sehingga total unit tanaman yaitu 18 x $4=72$ unit tanaman.

\section{Tahapan penelitian}

1. Persiapan lokasi dan naungan

2. Persiapan semai

3. Persiapan media tanam berupa tanah topsoil dan kompos

Pembuatan dan persiapan media tanam

1. Setelah tanah dan kompos dikering anginkan, kemudian tanah topsoil dan kompos dicampur dengan perbandingan 7 : 3 (Indriyanto, 2013)

2. Kemudian media dimasukkan ke dalam polybag dan ditimbang setiap polybagnya agar ukuran tanah dan beratnya sama. Berat untuk 1 ukuran polybag yaitu $2 \mathrm{~kg}$.

3. Media diinkubasi selama 3-4 hari kemudian siap dilakukan penanaman.

\section{Pemindahan Semai}

Pemindahan semai dilakukan setelah semua bahan yang akan digunakan tersedia dan dilakukan pada sore hari.

\section{Pemeliharaan Bibit}

1. Penyiraman

2. Penyiangan gulma

3. Perlindungan hama dan penyakit pada bambang lanang

\section{Variable Pengamatan}

Variabel yang Diamati

1. Tinggi tanaman (cm), pengukuran menggunakan penggaris mulai dari pangkal atau leher akar hingga titik tumbuh tertinggi.

2. Diameter tanaman (mm), diukur menggunakan caliper pada permukaan leher akar.

3. Jumlah daun tanaman (helai), yang dihitung adalah daun yang sudah terbuka sempurna. 
4. Panjang akar primer $(\mathrm{cm})$, diukur dari leher akar hingga ujung akar dengan menggunakan penggaris

5. Luas daun $\left(\mathrm{cm}^{2}\right)$, diukur pada akhir pengamatan menggunaakan ImageJ.

6. Berat Berangkasan Basah (g)

Pengukuran berat berangkasan basah dilakukan pada akhir penelitian 90 HST dengan beberapa sampel ulangan tanaman pada masing-masing perlakuan yang paling baik dari jumlah daun terbanyak dan dibersihkan serta dikering anginkan (tidak ada air) kemudian memisahkan bagian akar, batang, dan daun lalu ditimbang masing-masing bagian menggunakan timbangan analitik dengan satuan unit gram (g) tingkat ketelitian timbangan $0,1 \mathrm{~g}$.

7. Berat Berangkasan Kering (g)

Pengukuran berat berangkasan kering bibit diperoleh dengan cara mengoven masing-masing bagian akar, batang dan daun dari berat brangkasan basah sebelumnya pada suhu $80{ }^{\circ} \mathrm{C}$ selama 2x24 jam lalu ditimbang menggunakan timbangan analitik dengan satuan unit gram (gr) tingkat ketelitian timbangan 0,01 g.

8. Indeks Mutu Bibit (IMB)

Indeks mutu bibit diukur pada akhir pengamatan dengan menggunakan alat oven dan timbangan. Kualitas bibit dihitung dengan persamaan berikut :

Keterangan :

$$
\mathrm{Q}=\frac{B K T(g 0+B K A(g)}{\frac{T(\mathrm{~cm})}{D(\mathrm{~mm})}+\frac{B K T(\mathrm{~g})}{B K A(g)}}
$$

Q : indeks mutu bibit

BKT : Berat kering tajuk

D : diameter

BKA : Berat kering akar

T : Tinggi

(Indriyanto, 1999)

\section{Analisis data}

Data hasil pengamatan dianalisis dengan Uji $t$ untuk mengetahui perbedaan rata-rata dua varian yaitu :

1. Perlakuan asap cair dan kontrol

2. Perlakuan konsentrasi asap cair dan kontrol

3. Perlakuan antar konsentrasi asap cair Dengan menggunakan rumus :

1. Varian yang sama (equal variance) menggunakan rumus Polled Varians

$$
\begin{aligned}
t= & n 1-1 s 12+(n 2-1) \sin 22 n 1 \\
& +n 2(1 n 1+1 n 2)
\end{aligned}
$$

2. Varian yang sama (unequal variance) menggunakan Separated Varians :

$$
t=\quad s 12 n 1+522 n 2
$$

Keterangan :

$\mathrm{t}=$ nilai $\mathrm{t}$

$\bar{X}_{1}=$ rata rata data kelompok 1

$\overline{X_{2}}=$ rata-rata data kelompok 2

$\mathrm{S}^{2}=$ Estimasi perbedaan kelompok

$\mathrm{n} 1$ = banyaknya sampel pengukuran kelompok 1

$\mathrm{n} 2$ = banyaknya sampel pengukuran kelompok 2.

\section{BAB III \\ HASIL DAN PEMBAHASAN}

Keragaan Nilai Rata-Rata dan Standar Deviasi Variabel Pengamatan Semai Bambang Lanang (Michella champaca L) pada Minggu Terakhir

Hasil dari nilai rata-rata dan standar deviasi setiap perlakuan konsentrasi asap cair pada Tabel 1 menunjukkan bahwa ratarata terbesar untuk variabel tinggi terdapat pada perlakuan konsentrasi $1 \%$. Rata-rata terbesar untuk variable diameter, jumlah daun, luas daun, panjang akar, berat basah total, berat kering total terdapat pada perlakuan konsentrasi $2 \%$. 
Table 1. Nilai rata-rata dan standar deviasi perlakuan konsentrasi setiap variabel pengamatan pada minggu terakhir

\begin{tabular}{cccccc}
\hline Varia & \multicolumn{4}{c}{ Konsentrasi } & Kon \\
bel & $1 \%$ & $2 \%$ & $3 \%$ & $4 \%$ & trol \\
\cline { 2 - 5 } penga & X/SD & X/SD & X/SD & X/SD & X/S \\
matan & & & & & D \\
\hline Tingg & 28,27 & 25,67 & 26,08 & 23,08 & 26,2 \\
i & $\pm 5,2$ & $\pm 4,4$ & $\pm 5,5$ & $\pm 6,9$ & \pm 1, \\
& 2 & 6 & 0 & 0 & 9 \\
Diam & 5,76 & 5,99 & 5,48 & 5,32 & 5,6 \\
eter & $\pm 0,5$ & $\pm 0,8$ & $\pm 0,9$ & $\pm 1,4$ & \pm 0 \\
& 6 & 2 & 4 & 2 & 3 \\
Jumla & 12,66 & 13,94 & 13,27 & 12,94 & 12,8 \\
h & $\pm 1,8$ & $\pm 1,6$ & $\pm 1,9$ & $\pm 3,8$ & \pm 1 \\
Daun & 1 & 9 & 6 & 7 & 4 \\
Panja & 18,88 & 23,66 & 17,62 & 19,5 & $18 \pm$ \\
ng & $\pm 7,1$ & $\pm 5,5$ & $\pm 4,3$ & $\pm 6,4$ & 8,3 \\
akar & 0 & 1 & 1 & 9 & \\
Berat & 24,22 & 29,11 & 20,77 & 20,22 & $24 \pm$ \\
beran & $\pm 4,0$ & $\pm 6,6$ & $\pm 4,4$ & $\pm 5,3$ & 2,9 \\
gkasa & 8 & 2 & 0 & 0 & \\
n & & & & & \\
basah & & & & & \\
Berat & 4,71 & 5,29 & 4,09 & 3,08 & 4,4 \\
beran & $\pm 0,9$ & $\pm 1,2$ & $\pm 0,8$ & $\pm 0,8$ & \pm 0, \\
gkasa & 3 & 8 & 3 & 8 & 6 \\
n & & & & & \\
kerin & & & & & \\
g & & & & & \\
\hline & & & & &
\end{tabular}

Keterangan $=\mathrm{X}:$ rata-rata

SD : Standar deviasi

Hasil penelitian lain menyebutkan bahwa konsentrasi $2 \%$ mampu meningkatkan tinggi dan diameter pada tanaman jabon, sedangkan konsentrasi $1 \%$ sudah mampu meningkatkan pertumbuhan tinggi dan diameter pada tanaman sengon (Komarayati $d k k$., 2013). Penelitian tersebut menunjukkan kesamaan pada penelitian Bambang Lanang dimana konsentrasi 2\% memiliki rata-rata terbesar dari konsentrasi lainnnya pada variabel tinggi semai Bambang Lanang.
Setiap jenis tanaman memilki respon yang berbeda terhadap perlakuan pemberian asap cair. Penelitian lain menyebutkan penambahan $4 \%$ asap cair meningkatkan pertumbuhan anakan Gyrinossp melalui pertumbuhan tinggi dan diameter anakan secara nyata (Gusmailina $d k k$, 2018). Perlakuan asap cair konsentrasi 20\%/ tanaman cenderung meningkatkan pertambahan tinggi bibit, pertambahan jumlah daun dan luas daun bibit kelapa sawit (Sulistyanti $d k k, 2016)$. Muhakka $d k k$ (2013) pada penelitiannya menunjukkan bahwa pemberian asap cair terbaik pada tinggi tanaman rumput raja pada perlakuan konsentrasi $4 \%$ sedangkan pada jumlah anakan dan helai daun terbaik terdapat pada perlakuan konsentrasi $2 \%$.

\section{Pengaruh Perlakuan Asap Cair terhadap Pertumbuhan Semai Bambang Lanang (Michelia champaca $\mathbf{L}$ )}

Tabel 1 menunjukkan bahwa pemberian asap cair tidak memberikan perbedaan nyata, terlihat bahwa antara perlakuan asap cair dengan control tidak beda nyata pada semua variabel pengamatan. Pemberian asap cair belum memberikan pengaruh bagi pertumbuhan semai Bambang Lanang. Keterangan tidak berbeda nyata juga diperkuat dengan uji masing-masing konsentrasi dibanding kontrol .

Hal ini diduga bahwa pemberian dosis asap cair pada semai Bambang Lanang masih terlalu kecil yaitu hanya berkisar 0,2 $\mathrm{ml}$ hingga $4 \mathrm{ml}$. berbeda pada penelitian lain dimana Komarayati dan Pari (2014) melakukan penelitian pada pemberian dosis asap cair $100 \mathrm{ml}$ pertanaman dan menghasilkan pertumbuhan tanaman Jabon serta Sengon terbaik pada pemberian konsentrasi 2\%. Gusmailini dkk. (2018) melakukan penelitian dengan pemberian dosis asap cair $100 \mathrm{ml}$ pertanaman menghasilkan pertumbuhan tanaman 
Grynops sp terbaik terdapat pada pemberian konsentrasi 4\%. Penelitian lainnya menyatakan untuk pemberian dosis asap cair $10 \mathrm{ml} /$ bibit telah mampu meningkatkan pertumbuhan tinggi, diameter, berat kering total dan indeks mutu bibit cempaka yang lebih baik daripada kontrol. Penelitian Yuningsih $d k k$. (2015) menyatakan bahwa pada pemberian dosis asap cair $50 \mathrm{ml}$ berpengaruh nyata meningkatkan pertumbuhan tinggi, jumlah daun, luas daun, lingkar batang, dan berat kering bibit pada tanaman kakao, serta diikuti dengan dosis $100 \mathrm{ml}$.

Tabel 2. Hasil Uji t antara perlakuan asap cair vs kontrol setiap variable pengamatan

\begin{tabular}{|c|c|c|c|}
\hline \multirow{3}{*}{$\begin{array}{l}\text { Variable } \\
\text { pengamat } \\
\text { an }\end{array}$} & \multicolumn{2}{|c|}{$\begin{array}{l}\text { Uji perlakuan vs } \\
\text { control }\end{array}$} & \multirow{3}{*}{$\begin{array}{c}\text { Keterang } \\
\text { an }\end{array}$} \\
\hline & $\begin{array}{c}\text { Perlakua } \\
\mathrm{n}\end{array}$ & Control & \\
\hline & $\mathrm{X} / \mathrm{SD}$ & $\mathrm{X} / \mathrm{SD}$ & \\
\hline $\begin{array}{l}\text { Tinggi } \\
(\mathrm{cm})\end{array}$ & $\begin{array}{c}25,78 / 5,7 \\
8\end{array}$ & $\begin{array}{c}26,2 / 1,9 \\
1\end{array}$ & Ns \\
\hline Diameter & $5,64 / 1$ & $\begin{array}{c}5,63 / 0,3 \\
2\end{array}$ & Ns \\
\hline $\begin{array}{l}\text { Jumlah } \\
\text { daun } \\
\text { (helai) }\end{array}$ & $\begin{array}{c}13,20 / 2,4 \\
9\end{array}$ & $\begin{array}{c}12,83 / 1 \\
47\end{array}$ & $\mathrm{Ns}$ \\
\hline $\begin{array}{l}\text { Luas daun } \\
\qquad(\mathrm{cm} 2)\end{array}$ & $\begin{array}{c}67,38 / 18 \\
89\end{array}$ & $\begin{array}{c}67,83 / 7 \\
02\end{array}$ & Ns \\
\hline $\begin{array}{l}\text { Panjang } \\
\text { akar }(\mathrm{cm})\end{array}$ & $\begin{array}{c}19,91 / 6,1 \\
3\end{array}$ & $\begin{array}{c}18,08 / 8, \\
30\end{array}$ & Ns \\
\hline Berat & $23,58 / 6,1$ & $24 / 2,96$ & Ns \\
\hline $\begin{array}{c}\text { Berangka } \\
\text { san Basah } \\
(\mathrm{g})\end{array}$ & 3 & & \\
\hline Berat & $4,47 / 1,12$ & $4,46 / 0,6$ & Ns \\
\hline $\begin{array}{l}\text { Berangka } \\
\text { san kering } \\
(\mathrm{g})\end{array}$ & & 5 & \\
\hline $\begin{array}{l}\text { Keterangar } \\
\mathrm{x} \text { : rata-rata } \\
\mathrm{SD}: \text { standa } \\
\mathrm{ns}: \text { tidak b }\end{array}$ & $\begin{array}{l}\text { deviasi } \\
\text { la nyata }\end{array}$ & & \\
\hline
\end{tabular}

Pada penelitian ini, pengaruh pemberian asap cair juga belum terlihat diduga asap cair belum dapat diserap sempurna oleh tanaman (Muhakka $d k k$., 2013). Pada rumput raja umur 4 bulan pada penelitian Muhakka $d k k$ (2013) belum memberikan perbedaan nyata terhadap tinggi tanaman. Hal ini kemungkinan bahwa pemberian asap cair pada tanaman masih memerlukan waktu untuk melihat pengaruhnya (Komarayati $d k k$., 2014); (Gusmailina $d k k ., 2018)$; (Komarayati $d k k$, 2016).

Komarayati $d k k$. (2014) melakukan penelitian asap cair selama 6 bulan menghasilkan pertumbuhan tinggi sengon, jabon dan pohon penghasil Gaharu yang lebih baik. Gusmailina dkk. (2018) melakukan penelitian asap cair selama 6 bulan menghasilkan pertumbuhan tinggi tanaman Grynops sp yang signifikan, Komarayati dan Wibisono (2016) melakukan penelitian asap cair selama 7 bulan menghasilkan pertumbuhan tinggi tanaman Shorea platyclado Sloot ex Fowx dan Shorea selanica Blume yang terbaik.

Pengaruh pemberian asap cair pada beberapa konsentrasi terhadap Semai Bambang Lanang (Michelia champaca $\mathrm{L}$ )

Hasil pada Tabel 2 menunjukkan terdapat perbedaan nyata antara pemberian konsentrasi asap cair pada semai Bambang lanang, yaitu pada variable tinggi, luas daun, panjang akar, berat basah total dan berat kering total. Tabel 3 dan Tabel 4 menunjukkan bahwa pemberian konsentrasi asap cair hanya optimum pada konsentrasi $2 \%$ dan konsentrasi $4 \%$ dapat menurunkan rata-rata pertumbuhan semai Bambang Lanang.

Tabel 3. Hasil uji t antara konsentrasi asap cair VS control setiap variable pengamatan

\begin{tabular}{ccccccc}
\hline \multirow{2}{*}{ Variabel } & \multicolumn{6}{c}{ Uji t } \\
\cline { 2 - 7 } pengamatan & 1 & 1 & 1 & 2 & 2 & 3 \\
& $\%$ & $\%$ & $\%$ & $\%$ & $\%$ & $\%$ \\
\hline
\end{tabular}




\begin{tabular}{|c|c|c|c|c|c|c|}
\hline & VS & VS & VS & VS & VS & VS \\
\hline & 2 & 3 & 4 & 3 & 4 & 4 \\
\hline & $\%$ & $\%$ & $\%$ & $\%$ & $\%$ & $\%$ \\
\hline Tinggi & Ns & Ns & $*$ & Ns & Ns & ns \\
\hline Diameter & Ns & Ns & Ns & Ns & Ns & ns \\
\hline $\begin{array}{l}\text { Jumlah } \\
\text { daun }\end{array}$ & $*$ & Ns & Ns & Ns & Ns & ns \\
\hline Luas daun & ns & Ns & Ns & Ns & $*$ & ns \\
\hline $\begin{array}{l}\text { Panjang } \\
\text { akar }\end{array}$ & ns & Ns & Ns & $*$ & Ns & ns \\
\hline $\begin{array}{c}\text { Berat } \\
\text { berangkasa } \\
\text { n basah }\end{array}$ & ns & Ns & Ns & $*$ & $*$ & ns \\
\hline $\begin{array}{c}\text { Berat } \\
\text { berangkasa } \\
\mathrm{n} \text { kering } \\
\end{array}$ & ns & Ns & Ns & $*$ & $*$ & ns \\
\hline $\begin{array}{r}\text { Keterangan } \\
*\end{array}$ & $\begin{array}{l}\text { be } \\
05)\end{array}$ & ia & & ya & 5 & \\
\hline
\end{tabular}

Komarayati dan Wibisono (2016) menyatakan bahwa perlakuan konsentrasi asap cair $1 \%$ mampu meningkatkan pertumbuhan tinggi pada Shorea platycado. Penelitian Komarayati et al (2013) juga menyatakan bahwa asap cair dengan konsentrasi $1 \%$ dapat meningkatkan pertumbuhan tinggi pada tanaman sengon. Komarayati dan Pari (2014) melakukan penelitian pada beberapa konsentrasi asap cair yang berbeda dan menghasilkan pertumbuhan tanaman jabon serta sengon terbaik pada pemberian konsentrasi $2 \%$.

Masing-masing komponen dalam asap cair memiliki peran yang berbeda-beda. Diketahui bahwa asap cair tingkat crude (mentah) masih memiliki kandungan tar yang di dalamnya mengandung senyawa benzopiren yang bersifat toksik. Hal ini juga disebutkan oleh (Girard, 1992) bahwa senyawa benzopiren memiliki pengaruh buruk karena bersifat karsinogenik. Gorbatov dkk. (1971) menyebutkan bahwa asap cair yang belum terdestilasi masih memiliki senyawa yang tidak diinginkan yaitu senyawa tar dan hidrokarbon posiklis aromatic (PAH). Asap cair tingkat crude merupakan tingkat asap cair yang belum didestilasi sehingga kandungan-kandungan tersebut jika terlalu pekat digunakan pada tanaman kemungkinan akan menghambat atau bersifat racun bagi tanaman. Sehingga konsentrasi asap cair yang tinggi dapat menjadi racun bagi tanaman (Komarayati dan Wibisono, 2016).

Tabel 4. Hasil Uji t perbedaan nyata antara konsentrasi asap cair pada setiap variable pengamatan

\begin{tabular}{ccccc}
\hline & \multicolumn{4}{c}{ kata-rata perlakuan } \\
Variable & \multicolumn{4}{c}{ konsentrasi asap cair } \\
\cline { 2 - 5 } pengamatan & $1 \%$ & $2 \%$ & $3 \%$ & $4 \%$ \\
& X/SD & X/SD & X/SD & X/SD \\
\hline Tinggi & 28,27 & 25,67 & 26,08 & 23,08 \\
& $\mathrm{a}$ & $\mathrm{ab}$ & $\mathrm{ab}$ & $\mathrm{b}$ \\
Diameter & 5,76 & 5,99 & 5,48 & 5,32 \\
& $\mathrm{a}$ & $\mathrm{a}$ & $\mathrm{a}$ & $\mathrm{a}$ \\
Jumlah & 12,66 & 13,94 & 13,27 & 12,94 \\
daun & $\mathrm{b}$ & $\mathrm{a}$ & $\mathrm{ab}$ & $\mathrm{ab}$ \\
Luas daun & 73,28 & 77,53 & 61,91 & 56,81 \\
& $\mathrm{ab}$ & $\mathrm{a}$ & $\mathrm{ab}$ & $\mathrm{b}$ \\
Panjang & 18,88 & 23,66 & 17,62 & 19,51 \\
akar & $\mathrm{ab}$ & $\mathrm{a}$ & $\mathrm{b}$ & $\mathrm{ab}$ \\
Berat basah & 24,22 & 29,11 & 20,77 & 20,22 \\
total & $\mathrm{ab}$ & $\mathrm{a}$ & $\mathrm{b}$ & $\mathrm{b}$ \\
Berat basah & 4,71 & 5,29 & 4,09 & 3,08 \\
kering & & & $\mathrm{b}$ & $\mathrm{b}$ \\
\hline
\end{tabular}

Keterangan $=\mathrm{X}:$ rata-rata

SD : Standar deviasi

Selain terdapat kandungan tar dan senyawa benzopiren yang bersifat racun, asap cair dengan bahan baku kayu karet juga mempunyai kandungan total asam lebih tinggi daripada asap cair dari bahan baku lainnya seperti tempurung kelapa, dan mempunyai kandungan senyawa phenol yang lebih rendah (Towaha $d k k ., 2013$ ) menyebutkan bahwa dimana $\mathrm{pH}$ (derajat keasaman) asap cair dari kayu karet sekitar 2,8. Hasil penelitian Vachlepi dan Ardika, (2019) menyatakan bahwa karakteristik asap cair dari kayu karet pada proses pirolisis selama 8 jam menghasilkan $\mathrm{pH}$ 2,81 dan 
kadar asap 8,2\%. Semakin tinggi tingkat keasaman, semakin sulit nutrisi tanah diserap karena berbagai reaksi kimia yang terjadi. Sebaliknya jika keasaman normal, tanaman lebih mudah menyerap nutrisi dalam tanah karena mudah larut dalam air. Pada pH 6,5 ke bawah atau masam, tanaman tidak dapat tumbuh dengan baik atau bahkan tanah sulit untuk ditanami. Hal ini disebabkan oleh sedikitnya nutrisi yang terkandung pada tanah dan meningkatnya kadar racun.

Indeks mutu bibit

Bibit dinilai siap tanam apabila memenuhi kriteria nilai IMB $\geq 0,09$ (Lackey \& Alm, 1982 dalam Hendromono, 2003). Terlibat bahwa pemberian asap cair dan control menghasilkan rerata indeks mutu bibit dengan kriteria biak. Nilai IMB setiap peningkatan konsentrasi bervariasi, tidak meningkat dan tidak menurun. IMB semua konsentrasi lebih baik dari control kecuali $3 \%$. Konsentrasi $2 \%$ memiliki nilai IMB paling besar dari pada control dan konsentrasi lainnya. Hal ini menunjukkan bahwa pemberian asap cair mampu meningkatkan Indeks Mutu Bibit bambang lanang.

Tabel 5. Indeks Mutu Bibit Bambang Lanang (Michelia champacha L) berdasarkan konsentrasi

(\%) asap cair.

\begin{tabular}{ccc}
\hline $\begin{array}{c}\text { Konsentra } \\
\text { si }\end{array}$ & IMB & $\begin{array}{c}\text { Kriteri } \\
\text { a }\end{array}$ \\
\hline $1 \%$ & 0,51721 & Baik \\
$2 \%$ & 0,67959 & Baik \\
& 7 & \\
$3 \%$ & 0,45857 & Baik \\
& 5 & \\
$4 \%$ & 0,47504 & Baik \\
& 5 & \\
kontrol & 0,46625 & Baik \\
& 5 & \\
\hline
\end{tabular}

\section{BAB IV KESIMPULAN}

1. Semai Bambang Lanang memberikan respon tidak berbeda nyata terhadap pemberian asap cair, namun memberikan rata-rata nilai yang lebih besar daripada kontrol (tanpa perlakuan)

2. Semai Bambang Lanang memberikan respon nyata terhadap pemberian konsentrasi asap cair yaitu pada variabel tinggi, luas daun, panjang akar, berat berangkasan basah dan kering. Rata-rata perlakuan pada konsentrasi asap cair $2 \%$ menunjukkan nilai yang lebih besar dari pada konsentrasi $1 \%, 3 \%$ dan $4 \%$.

\section{DAFTAR PUSTAKA}

Departemen Kehutanan, 2009. Roadmap Penelitian dan Pengembangan Kehutanan 2010-2025. Badan Penelitian dan Pengembangan Kehutanan, Jakarta.

Girard, JP, 1992. Smoking in Technology of Meat Product, New York : Clermont Ferrand, Ellis Horwood.

Gorbatov, VM, NN Kyrlova, VP Volovinskaya, YN Cyaskovkaya, KI Bazarova, RI Khlamova and GY. Yakavlova, 1971. Liquid Smoke for Use in Cured Meat. Food. Tech 25:71-77.

Gusmailina, S. Komarayati dan HS. Wibisono, 2018. Pengaruh arang dan asap cair terhadap pertumbuhan anakan Gyrinops sp. Penelitian Hasil Hutan 36(1) :23-31

Hendromono, 2003. Kriteria Penilaian Mutu Bibit dalam Wadah yang Siap Tanam untuk Rehabilitasi Hutan dan Lahan. Buletin Penelitian dan Pengembangan 
Kehutanan 4(1) : 11-20. Badan Litbang Kehutanan, Jakarta.

Indriyanto, 1999. Pengaruh periode penyapihan dan media penyapihan terhadap kualitas pertumbuhan bibit mahoni. Buletin Kehutanan 39: 1220 .

Komarayati, S.Gusmailina dan G.Pari,2011. Produksi cuka kayu hasil modifikasi tungku arang terpadu. Jurnal Penelitian Hasil Hutan 29(3): 234247.

Komarayati, S dan G. Pari, 2014. Pengaruh arang dan cuka kayu terhadap pertumbuhan jabon dan sengon. Penelitian Hasil Hutan 32(1) : 12-20.

Komarayati, S dan HS. Wibisono, 2016. Pengaruh penambahan arang dan cuka kayu terhadap pertumbuhan anakan Shorea platyclados S.Loot ex Fown dan Shorea selanica Blume. Jurnal Penelitian Hasil Hutan 34 (4) : 349-357.

Martin, E , M. Ulfa, A. Silalahi dan B. Winarno, 2003. Agroforestry Tradisional sebagai Basis Pengembangan Hutan Rakyat. Prosiding Ekspose Hasil-hasil Penelitian UPT Badan Litbang Kehutanan Wilayah Indonesia Barat. Puslitbang Bioteknologi dan Pemuliaan Tanaman Hutan. Yogyakarta.

Martin, E dan BT. Premono, 2010. Hutan Tanaman Kayu Pertukangan adalah Portofolio : Pelajaran dari Penyebarluasan Bambang Lanang di Masyarakat. Prosiding Seminar Nasional : Kontribusi Litbang dalam Peningkatan Produktivitas dan
Kelestarian Hutan, Bogor 29 November 2010. Pusat Litbang Peningkatan Produktivitas Hutan, Bogor.

Muhakka, A. Napoleon dan H. Isti'adah, 2013. Pengaruh Pemberian Asap Cair terhadap Pertumbuhan Rumput Raja (Pennisetum purpureophaides). Pastura 3(1): 30-34.

Nurhayati, T., 2007. Produksi arang terpadu dengan cuka kayu dan pemanfaatan cuka kayu pada tanaman pertanian. Makalah pada acara pelatihan pembuatan arang terpadu dan produk turunannya. Dinas Kehutanan Kabupaten Bulungan, Kalimantan Timur, 17-26 Juli 2007.

Sofyan, A., E. Martin, AH Lukman dan AW Nugroho, 2010. Status Riset dan Rencana Penelitian Jenis-jenis Prioritas Kayu Pertukangan di Sumatera. Dalam Peran litbang Kehutanan dalam Implementasi RSPO. Prosiding Seminar Bersama BPK Aek Nauli, BPK Palembang, dan BPHPS Kuok, tanggal 4-5 November 2010 di Pekanbaru. Pusat Penelitian dan pengembangan Hutan dan Konservasi Alam.

Sulistyanti, ERS. Ardian dan SI. Saputra, 2016. Pemberian Asap Cair TKKS dan Trichokompos pada Bibit Kelapa sawit (Elais guinensis Jacq.) di pembibitan Utama. JOM Faperta 3 (2) 